\title{
Three-dimensional printing applications in the neurosurgery: A pilot study
}

\author{
Moneer K. Faraj ${ }^{1}$ D , Bassam Arkawazi ${ }^{2}$, Aqeel Kareem Hatim ${ }^{3}$ D Zaid Al-Attar $^{4 *}$ (D) \\ ${ }^{1}$ Department of Surgery, Consultant Neurosurgeon, College of Medicine, University of Baghdad, Baghdad, Iraq; ${ }^{2}$ Department of \\ Surgery, Al-Kindy College of Medicine, University of Baghdad, Baghdad, Iraq; ${ }^{3}$ Lecturer of Neurology, College of Medicine, University \\ of Baghdad, Baghdad, Iraq; ${ }^{4}$ Department of Pharmacology, Al-Kindy College of Medicine, University of Baghdad, Baghdad, Iraq
}

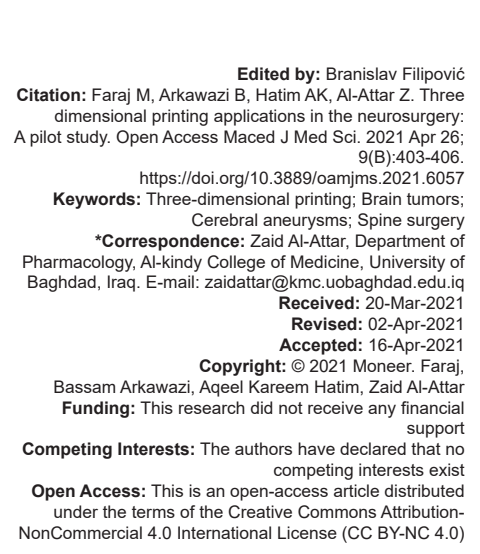

\section{Introduction}

The history of three-dimensional (3D) printing began in 1981 with Hideo Kodama's patented application for a rapid prototyping device. Kodama was the first person ever to apply for a patent in which laser beam resin curing system is described [1].

In 1986 Jane Cloward Oliver de Witte and Alaine Le Mehaute from issued a patent for 3D printer, and in the same year, Charlies started his own company in California (3D System). They released their first commercial project in 1988 named SLA-1 Stereolithography [2].

In 1988 two 3D printing technologies were invented. The first was selective laser sintering (SLS) patent filed by Carl Deckard from The University of Texas, and the second technique called fused deposition modeling (FDM) created by Scott and Leisure, the founders of Stratasys.

FDM is an additive manufacturing (AM) process in which a physical object is created directly from a computer-aided design model using layer-by-layer deposition of a feedstock plastic filament material extruded through a nozzle, interestingly, now being the simplest and most common of the three technologies [3].

\section{Patients and Methods}

We started our 3D laboratory by personal finance. It was established in the neuroscience hospital in Baghdad/Iraq

We had an $\mathrm{X}, \mathrm{Y}, \mathrm{Z}$ printer. The working team included neurosurgeons, biomedical engineers, and bio-technicians. The process started with self-education and training with frequent trial and error processing.

The procedure starts with obtaining magnetic resonance imaging (MRI) or computed tomography (CT) scan in particular protocols including axial, coronal, and sagittal views of the targeted area, of 1-1.5 mm thickness with 0 gap, square image, and no gantry tilt. 
The MRI, and CT or angiography images were imported into a 3D programmer for DICOM images called $3 \mathrm{D}$ slice where these files converted into a $3 \mathrm{D}$ pictures (Figure 1).

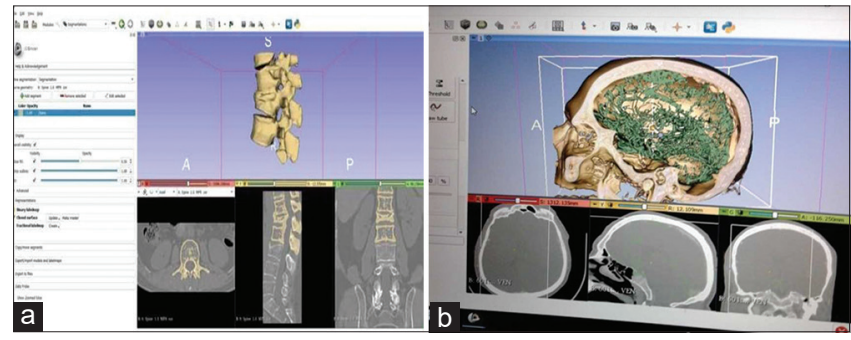

Figure 1: Computed tomography images converted into a three dimensional pictures (a) spine and (b) brain

Next, the neurosurgeon determines the cut section he needs to print. The final required object is exported to the $\mathrm{X}, \mathrm{Y}, \mathrm{Z}$ printing software where the technician starts to print it out.

The final prototype delivered to the neurosurgeon. He uses it intraoperatively to have an apparent actual size 3D representation of the actual lesion with nearby healthy tissues to have a good idea about the case he manages.

\section{Results}

This pilot study was divided into three major projects.

\section{Brain tumors}

We used this technique for ten cases of brain tumors from July 2018 to July 2019. All patients had deepseated brain tumors. We made a 3D print cast revealing the normal and edematous cerebral cortex that covers the deep-seated tumor. This prototype used by the neurosurgeon just like the navigator. He evaluates the shape of the brain convolutions intraoperatively with that in the printing cast in order to determine the safest entry point and trajectory to the lesion just like the navigator (Figure 2).

\section{Cerebral aneurysms}

A CT angiography used to produce 3D printing models of actual size for intracranial aneurysms with their nearby blood vessels.

The samples delivered to the neurosurgeon preoperatively to have a clear image of the aneurysm with its associated blood vessels. He can determine even the shape, and the length of the required aneurysmal clip needed.

We have operated upon nine cases during the same period using this technology (Figure 3 ).

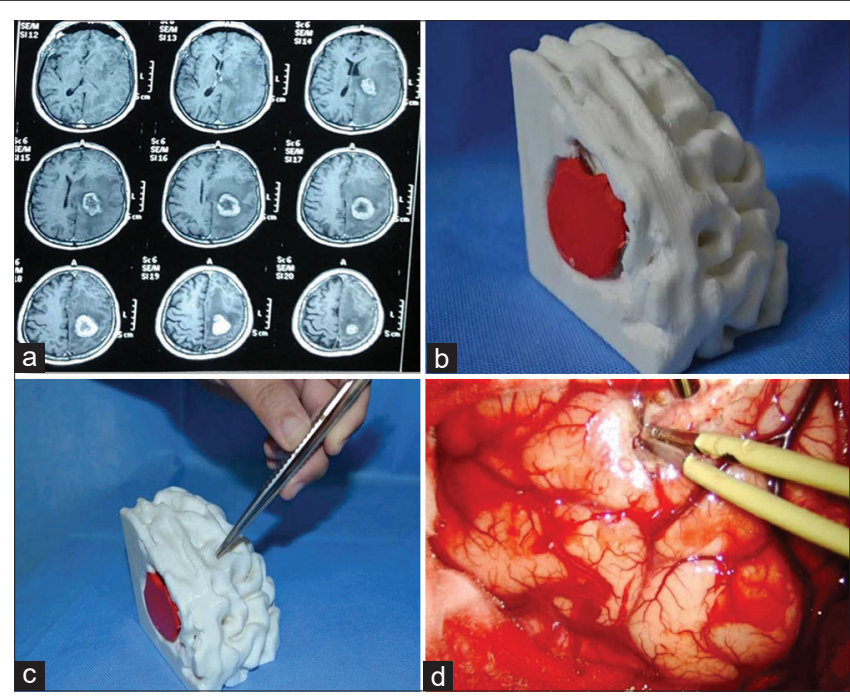

Figure 2: (a) Axial view magnetic resonance imaging showing a deep seated metastatic tumor in the left parietal lobe (b) three dimensional printing model showing the tumor and the surrounding cerebral tissue (c) determining the entry point and the trajectory (d) intraoperative point of entry

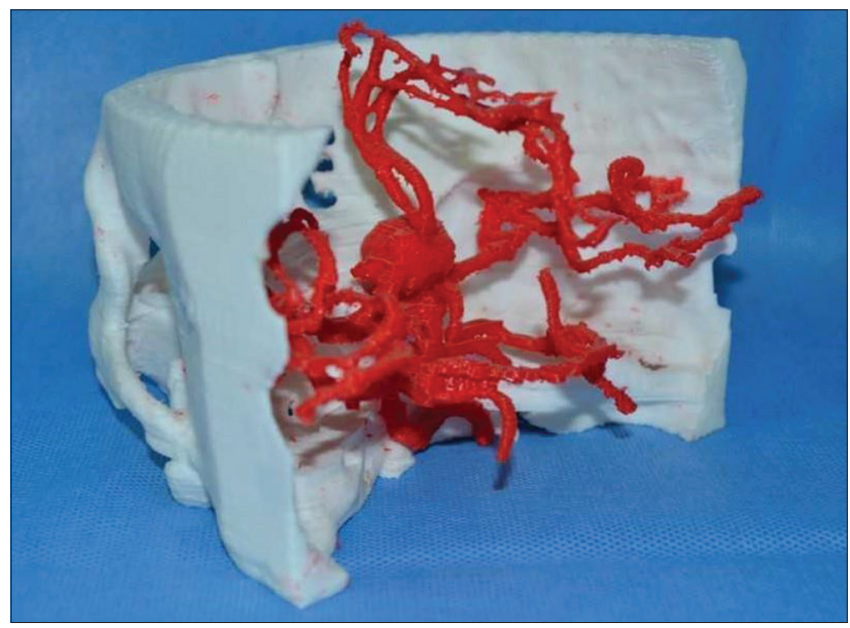

Figure 3: A three dimensional printing model showing an anterior communicating artery aneurysm and its relation to the surrounding vessels and skull bones

\section{Spine surgery}

3D printing models used in five cervical spine cases. Two cases had craniocervical junction traumatic injuries. The printing model gave a clear idea about the relation of the lower occiput with the upper cervical spine. It facilitated the management of fixation (Figure 4).
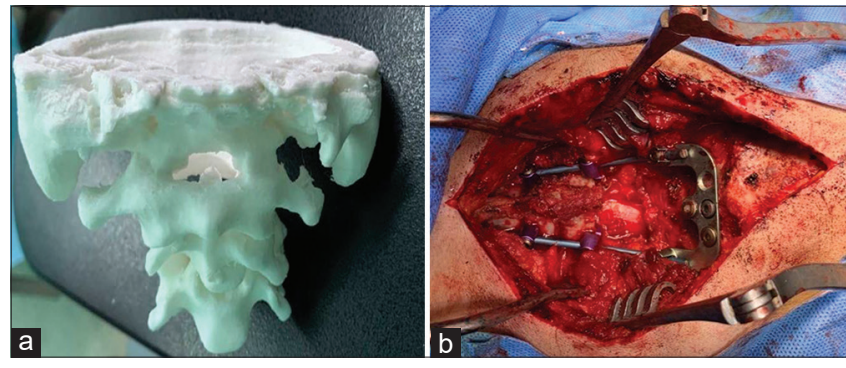

Figure 4: (a) A three dimensional printing model showing the relation of the occipital bone to the upper cervical vertebrae. (b) Intraoperative craniocervical fixation 
The other three cases needed lower cervical posterior fixation. The prototype cast helped us to determine the entry point, the trajectory, the size, and the length of the screws needed even preoperatively (Figure 5).

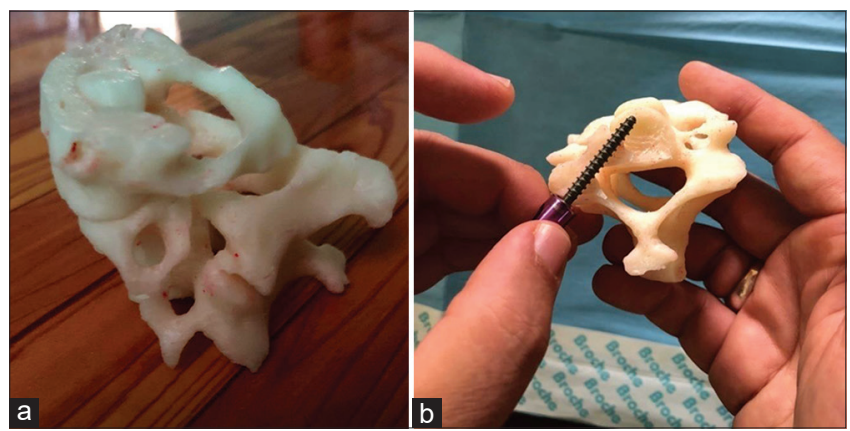

Figure 5: (a) A three dimensional printing model of the lower cervical vertebrae. (b) Determining the entry point, the trajectory, the size, and the length of the screws needed preoperatively

This technique was also used in patients with spinal spondylolisthesis and traumatic spinal fractures. We build up 3D printing models of the involved vertebrae with the above and below vertebrae. This helped us to determine the entry point, the trajectory, the size, and the length of the screws needed preoperatively. This technique was used for nine patients (Figure 6).

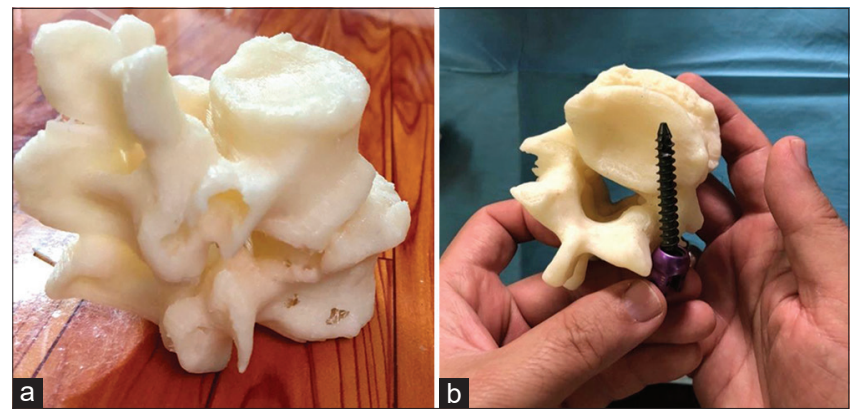

Figure 6: (a) A three dimensional printing model of the lumbar vertebrae. (b) Determining the entry point, the trajectory, the size, and the length of the screws needed preoperatively

In all these cases we noticed that the duration of surgery was much less than the conventional ones and the neurosurgeon had more confidence to do the surgery while he has an actual real size 3D print of the lesion preoperatively with good preoperative evaluation of the pathology and its relation to normal nearby tissues.

Table 1: A comparison between 3D printing and other modalities in cranial surgery

\begin{tabular}{lll}
\hline Criteria & 3D printing & Other modalities \\
\hline Cost & Less & More \\
Time & Less & Longer \\
Precision & Precise & Precise \\
Team work & Team & Team \\
Limitations & Anatomical shift & Anatomical shift \\
\hline 3D: The
\end{tabular}

3D: Three dimensional.

\section{Discussion}

The utilization of 3D printing in neurosurgery is still a new technology. Many centers tried to perform it for different medical specialties, especially faciomaxillary and orthopedic surgery [4].

Table 2: A comparison between 3D printing and conventional surgery in vascular surgery

\begin{tabular}{lll}
\hline Criteria & 3D printing & Conventional \\
\hline Cost & Same & Not available \\
Time & Less & Longer \\
Precision & Precise & Precise \\
Team work & Team & Team \\
Limitations & Anatomical shift & Anatomical shift \\
\hline 3D: Three dimensional. & &
\end{tabular}

In neurosurgery, its use is still under evaluation [5], [6], [7], [8], [9], [10]. In our pilot study, we noticed the following privileges as summarized in Tables 1-3.

Table 3: A comparison between 3D printing and other modalities in spinal surgery

\begin{tabular}{lll}
\hline Criteria & 3D printing & Other modalities \\
\hline Cost & Less & More \\
Time & Less & Longer \\
Radiation exposure & Much less & Higher \\
Precision & Precise & Precise \\
Team work & Team & Team \\
Implantable materials & Non & Non \\
\hline
\end{tabular}

3D: Three dimensional.

\section{Conclusion}

3D printing has excellent advantages in neurosurgical practice. It can replace many other recent modalities. It enables the neurosurgeon works with more precision, less time-consuming, less cost, and less radiation exposure.

\section{Authors Contribution}

Moneer K. Faraj: Design of study. Bassam Mahmood Flamerz Arkawazi: Collection of data. Dr Zaid Al-Attar: analysis of data and editing.

\section{References}

1. Watanabe E. 3D Printer and Its Impact on Neurosurgery. No Shinkei Geka. 2015;43(11):967-76.

PMid:26549716

2. Leal A, Souza M, Nohama P. Additive manufacturing of $3 D$ biomodels as adjuvant in intracranial aneurysm clipping. Artif Organs. 2019;43(1):E9-15. https://doi.org/10.1111/aor.13303 PMid:30357865

3. Waqas M, Mokin M, Lim J, Vakharia K, Springer ME, Meess KM, et al. Design and physical properties of 3-dimensional printed models used for neurointervention: A systematic review of the literature. Neurosurgery 2020;87(4):E445-53. https://doi. org/10.1093/neuros/nyaa134

PMid:32392300 
4. Cho J, Park CS, Kim YJ, Kim KG. Clinical application of solid model based on trabecular tibia bone CT images created by 3D printer. Healthc Inform Res. 2015;21(3):201-5. https://doi. org/10.4258/hir.2015.21.3.201

\section{PMid:26279958}

5. Lan Q, Zhu Q, Xu L, Xu T. Application of 3D-printed craniocerebral model in simulated surgery for complex intracranial lesions. World Neurosurg. 2020;134:e761-70. https://doi.org/10.1016/j. wneu.2019.10.191

PMid:31712116

6. Nagassa RG, McMenamin PG, Adams JW, Quayle MR, Rosenfeld JV. Advanced 3D printed model of middle cerebral artery aneurysms for neurosurgery simulation. 3D Print Med. 2019;5(1):11. https://doi.org/10.1186/s41205-019-0048-9 PMid:31372773

7. Bairamian D, Liu S, Eftekhar B. Virtual reality angiogram vs 3-dimensional printed angiogram as an educational tool-a comparative study. Neurosurgery. 2019;85(2):E343-9. https:// doi.org/10.1093/neuros/nyz003

PMid:30715444

8. Choy WJ, Parr WC, Phan K, Walsh WR, Mobbs RJ. 3-dimensional printing for anterior cervical surgery: A review. J Spine Surg. 2018;4(4):757-69. https://doi.org/10.21037/jss.2018.12.01 PMid:30714008

9. Lador R, Regev G, Salame K, Khashan M, Lidar Z. Use of 3-dimensional printing technology in complex spine surgeries. World Neurosurg. 2020;133:e327-41. https://doi.org/10.1016/j. wneu.2019.09.002

PMid:31520760

10. Parr WC, Burnard JL, Wilson PJ, Mobbs RJ. 3D printed anatomical (bio)models in spine surgery: Clinical benefits and value to health care providers. J Spine Surg. 2019;5(4):549-60. https://doi.org/10.21037/jss.2019.12.07

PMid:32043006 